\title{
SISTEMA BRASILEIRO DE PRECEDENTES JUDICIAIS OBRIGATÓRIOS E OS DEVERES INSTITUCIONAIS DOS TRIBUNAIS: UNIFORMIDADE, ESTABILIDADE, INTEGRIDADE E COERÊNCIA DA JURISPRUDÊNCIA ${ }^{1}$.
}

\author{
BRAZILIAN SYSTEM OF PREVIOUS MANDATORY LEGAL AND \\ CONSTITUTIONAL DUTIES OF THE COURTS: UNIFORMITY, STABILITY, \\ COMPLETENESS AND CONSISTENCY OF LAW
}

Fredie Souza Didier Junior ${ }^{2}$

Resumo: O presente artigo tem por finalidade examinar o sistema de precedentes obrigatórios no Direito brasileiro, introduzido pelo novo Código de Processo Civil brasileiro, cuja vigência inicia-se em março de 2016, haja vista que um dos pilares do novo Código é a estruturação dogmática de um sistema de precedentes judiciais obrigatórios. Analisar-se-á os deveres institucionais dos Tribunais no que tange ao sistema de precedentes, especialmente no que tange à uniformidade, a estabilidade, integridade e coerência da jurisprudência, com fins de estruturar o sistema de precedentes brasileiro.

Palavras-chave: NOVO CÓDIGO DE PROCESSO CIVIL. PRECEDENTES JUDICIAIS OBRIGATÓRIOS. UNIFORMIDADE, ESTABILIDADE, INTEGRIDADE E COERÊNCIA DA JURISPRUDÊNCIA.

Abstract: This article aims to examine the previous system required under Brazilian law, introduced by the new Brazilian Civil Procedure Code, whose term begins in March 2016, given that one of the pillars of the new Code is the dogmatic structure of a system of mandatory judicial precedents. Analyze will be given to the institutional duties of the courts in relation to the previous system, especially with regard to uniformity, stability, integrity and consistency of jurisprudence, for purposes of structuring the Brazilian previous system.

\footnotetext{
1 Em homenagem a Nicola Picardi.

2 Doutor pela Pontifícia Universidade Católica de São Paulo. Professor associado da Universidade Federal da Bahia, Salvador, Bahia, Brasil.
} 
Keywords: NEW CODE OF CIVIL PROCEDURE. MANDATORY LEGAL PRECEDENT. UNIFORMITY, STABILITY, COMPLETENESS AND CONSISTENCY OF JURISPRUDENCE.

\section{NOTA INTRODUTÓRIA.}

Em março de 2015 foi promulgado o novo Código de Processo Civil brasileiro (CPC). A partir de março de 2016, fica revogado o Código de Processo Civil de 1973 (CPC-1973).

Um dos pilares do novo Código é a estruturação dogmática de um sistema de precedentes judiciais obrigatórios. Essa transformação do direito brasileiro deve-se muito ao modo pelo qual a jurisdição vem sendo examinada pelos estudiosos do Direito no Brasil.

Nicola Picardi, em texto célebre e muito difundido no Brasil, fala da "vocação do nosso tempo para a jurisdição"3. O Direito processual civil brasileiro é, hoje, uma comprovação da intuição do mestre italiano.

Esse ensaio, que tem por objetivo examinar uma parte nuclear do sistema de precedentes obrigatórios no Direito brasileiro, é, assim, a singela homenagem de um jovem brasileiro a um dos mais influentes juristas italianos.

\section{DEVERES INSTITUCIONAIS DOS TRIBUNAIS RELACIONADOS AO SISTEMA DE PRECEDENTES.}

O art. 926 CPC brasileiro inova ao dispor que "os tribunais devem uniformizar sua jurisprudência e mantê-la estável, íntegra e coerente".

Prevê, assim, deveres gerais para os tribunais no âmbito da construção e manutenção de um sistema de precedentes (jurisprudência e súmula), persuasivos e obrigatórios, sendo eles: a) o dever de uniformizar sua jurisprudência; b) o dever de manter essa jurisprudência estável; c) o dever de integridade; e d) o dever de coerência.

Todos eles são decorrência de um conjunto de normas constitucionais: dever de motivação, princípio do contraditório, princípio da igualdade e segurança jurídica.

\footnotetext{
${ }^{3}$ PICARDI, Nicola. "La vocazione del nostro tempo per la giurisdizione". Rivista Trimestrale di Diritto e Procedura Civile. Milano: Giuffrè, 2004, n. 1, p. 41 e segs.
} 
Mas isso não elimina a relevância de sua previsão no plano infraconstitucional. A consagração legislativa explicita diretamente o comportamento exigido dos tribunais na atividade de elaboração e desenvolvimento de um direito judicial.

Cabe analisar cada um desses deveres.

\section{DEVER DE UNIFORMIZAÇÃO DA JURISPRUDÊNCIA.}

O dever de uniformizar pressupõe que o tribunal não possa ser omisso diante de divergência interna, entre seus órgãos fracionários, sobre a mesma questão jurídica ${ }^{4}$. O tribunal tem o dever de resolver essa divergência, uniformizando o seu entendimento sobre o assunto.

$\mathrm{O}$ art. 926, $\S 1^{\circ}, \mathrm{CPC}$, desdobra o dever de uniformizar, dele extraindo o dever dos tribunais de sintetizar sua jurisprudência dominante, sumulando-a, ao determinar que, "na forma estabelecida e segundo os pressupostos fixados no regimento interno, os tribunais editarão enunciados de súmula correspondentes a sua jurisprudência dominante". Esse dever fica condicionado ao cumprimento do disposto no art. 926, §2 ${ }^{\circ}$ CPC: "ao editar enunciados de súmula, os tribunais devem ater-se às circunstâncias fáticas dos precedentes que motivaram sua criação" 5 .

O objetivo é esclarecer que o correto exercício deste dever de editar enunciados sumulares pressupõe a fidelidade do tribunal à base fática a partir da qual a jurisprudência sumulada foi construída. Cumpre preservar o caráter de concretude do direto judicial que se constrói. Produz-se norma geral, mas a partir de casos concretos.

Com isso, o legislador "neutraliza o problema histórico dos enunciados das súmulas criados de forma abstrata, sem referência aos precedentes que levaram à sua conformação"6.

\footnotetext{
${ }^{4}$ Defendendo a existência de um dever de uniformizar a jurisprudência ainda sob a vigência do CPC1973, e apenas com base na previsão do incidente de uniformização de jurisprudência do CPC-1973 (arts. 476 e segs.), VIGLIAR, José Marcelo Menezes. Uniformização de jurisprudência - segurança jurídica e dever de uniformizar. São Paulo: Atlas, 2003, p. 203; SANTOS, Ernane Fidélis. Manual de Direito Processual Civil. $6^{a}$ ed. São Paulo: Saraiva, 1998, v. 1, p. 600; DIDIER Jr., Fredie; CUNHA, Leonardo Carneiro da. Curso de Direito Processual Civil. $12^{\mathrm{a}}$ ed. Salvador: Editora Jus Podivm, 2014, v. 3, p. 555.

${ }^{5}$ A súmula é uma consolidação de enunciados que consagram as teses jurídicas que têm prevalecido no tribunal. O enunciado da súmula propõe-se a ser o texto da ratio decidendi do precedente que vem sendo reiteradamente seguido em determinado tribunal.

${ }^{6}$ ZANETI JR., Hermes. O Valor Vinculante dos Precedentes. Salvador: JusPodivm, 2014, p. 380.
} 


\section{DEVER DE MANTER A JURISPRUDÊNCIA ESTÁVEL.}

Há, ainda, o dever de o tribunal manter sua jurisprudência estável.

Assim, qualquer mudança de posicionamento (superação; overruling) deve ser justificada adequadamente, além de ter sua eficácia modulada em respeito à segurança jurídica (art. 927, §4 ${ }^{\circ}$ CPC).

Daí falar-se em um princípio da "inércia argumentativa", como a norma que:

a) estabelece a necessidade de uma forte carga argumentativa para aquele que pretende afastar (por distinção ou superação) o precedente diante de caso que se assemelhe àquele que ensejou sua formação, exigindo-se não apenas a fundamentação ordinária nos termos do art. 489, caput e $\S 1^{\circ}, \mathrm{CPC}$, como também uma fundamentação qualificada que justifique o overruling ou distinguishing nos moldes do art. 489, $\S 1^{\circ}, \mathrm{VI}, \mathrm{CPC}$; e

b) facilita a elaboração da fundamentação (carga argumentativa mais fraca) para aquele que pretende aplicar o precedente à resolução de caso semelhante ${ }^{7}$, mas sem que se abra mão de, ao menos, identificar seus fundamentos determinantes e demonstrar que o caso sob julgamento se ajusta àqueles fundamentos (art. 489, $\$ 1^{\circ}$, $\mathrm{V}, \mathrm{CPC})$.

A "inércia argumentativa" vem em prol da preservação do status quo, cuja modificação pressupõe razões extras até então não cogitadas ou enfrentadas. Mais do que norma infraconstitucional (art. 489, $\$ 1^{\circ}, \mathrm{V}$ e VI, CPC), a "inércia argumentativa" encontra-se implicitamente consagrada na Constituição como exigência de uniformidade jurisprudencial que garanta: i) igualdade de tratamento para casos afins (art. 5 , caput, CF); ii) de motivação adequada tanto para a decisão que aplica como para aquela que afasta o precedente (art. 93, IX, CF); e iii) de contraditório, que pressupõe o direito de conhecer essa motivação para questioná-la por meios de impugnação cabíveis (art. 5, LV, CF) ${ }^{8}$.

\footnotetext{
7 ATAÍDE JUNIOR, Jaldemiro. O princípio da inércia argumentativa diante de um sistema de precedentes em formação no Direito brasileiro. Revista de Processo. São Paulo: RT, 2014, n. 229, p. 379 e 389.

8 ATAÍDE JUNIOR, Jaldemiro. O princípio da inércia argumentativa diante de um sistema de precedentes em formação no Direito brasileiro. Revista de Processo. São Paulo: RT, 2014, n. 229, p. 392 e 393.
} 
Uma última palavra: "a estabilidade da jurisprudência do tribunal depende também da observância de seus próprios precedentes, inclusive por seus órgãos fracionários" 9 .

\section{DEVER DE COERÊNCIA E DEVER DE INTEGRIDADE.}

\subsection{Premissas.}

O art. 926 do CPC atribui ao tribunal os deveres de manter íntegra e coerente a sua jurisprudência.

Este enunciado normativo é inédito e de difícil compreensão.

A começar pelo fato de ele incorporar dois termos muito difundidos nos estudos contemporâneos sobre a teoria do Direito, de um modo geral, e da decisão judicial, de um modo especial: a integridade e a coerência. Isso naturalmente leva o intérprete a relacionar o enunciado normativo a determinada concepção teórica a respeito do tema; sobretudo o termo "integridade", muito ligado às ideias de Ronald Dworkin ${ }^{10}$; já o termo "coerência", por outro lado, é bem disseminado.

Para que se possa ter uma dimensão do problema, há quem veja no termo "integridade", no sentido utilizado por Dworkin, sinonímia com o termo "coerência" 11. E, como se verá nos exemplos de concretização desses deveres, há clara interseção entre as suas zonas de aplicação.

Sucede que se está diante de um enunciado normativo, e não de um enunciado doutrinário. É preciso dar sentido normativo ao que dispõe a parte final do art. 926 do CPC.

Embora esse sentido possa ser construído a partir das lições de autores que se vincularam a esses termos, não há necessidade, e nem poderia ser diferente, de o conteúdo normativo desses textos corresponder exatamente a determinada orientação filosófica.

\footnotetext{
9 Enunciado n. 316 do Fórum Permanente de Processualistas Civis. O Fórum Permanente de Processualistas Civis é uma reunião semestral de processualistas brasileiros, cujo propósito é apresentar enunciados doutrinários que sirvam à compreensão do CPC brasileiro de 2015. Os enunciados somente podem ser aprovados por unanimidade.

10 DWORKIN, Ronaldo. O Império do Direito. Jeferson Luiz Camargo (trad.). São Paulo: Martins Fontes, 2003, p. 213-332.

11 PECZENIK, Alexsander. On law and reason. Lexington: Springer, 2009, p. 132. Essa sinonímia revela-se, com alguma clareza, na obra de autora expressamente influenciada pelo pensamento de Dworkin: BARBOZA, Estefânia Maria de Queiroz. Precedentes judiciais e segurança jurídica fundamentos e possibilidades para a jurisdição constitucional brasileira. São Paulo: Saraiva, 2014, p. 252.
} 
É preciso concretizar o conteúdo normativo desses deveres, de modo a que se possa construir e compreender o microssistema de formação, aplicação e revogação de precedentes do direito brasileiro.

a) Temos, então, uma primeira premissa: a discussão muda de patamar; não se trata mais apenas de uma querela filosófica - que continuará existindo, é claro, até mesmo pela relevância da discussão. O problema da interpretação do que se entende por "coerência" e por "integridade" passou a ser dogmático.

b) A segunda premissa para compreender o conteúdo dogmático do art. 926 do CPC é a seguinte: o uso de dois termos pelo legislador indica claramente a existência de dois deveres.

Há o dever de coerência e há o dever de integridade.

A interpretação do dispositivo deve ser no sentido de dar-lhe máxima efetividade; não parece adequada qualquer interpretação que compreenda o dever de integridade como continente do qual o dever de coerência é conteúdo, ou viceversa. A depender da concepção teórica a que se filie o intérprete, uma ou outra opção poderia revelar-se.

Há dois deveres, que, ao lado dos demais (uniformizar a jurisprudência, mantê-la estável e divulgá-la devidamente), compõem o complexo de situações jurídicas passivas imputadas aos tribunais. Tais deveres servem como instrumentos para o desenvolvimento do microssistema de precedentes judiciais obrigatórios brasileiros.

Há doutrina que simplesmente os mistura12; há quem, embora os distinga, quando trata de concretizá-los, refere a um e a outro indistintamente ${ }^{13}$; e ainda há quem prefira referir-se a eles utilizando o termo "consistência".

São dois os deveres; mas eles formam um amálgama. É bem difícil compreender um sem o outro.

c) Isso nos faz caminhar para a terceira premissa: a necessária distinção dogmática entre esses deveres não impede que uma determinada conduta devida pelo tribunal possa decorrer de ambos os textos normativos.

Ou seja: os dois deveres podem impor ao tribunal uma só conduta.

\footnotetext{
${ }^{12}$ Embora preferindo usar o termo "coerência", PECZENIK, Alexander. "Certainty or coherence". The reasonable as rational? On legal argumentation and justification. Festschrift for Aulis Aarnio. Berlin: Duncker \& Humblot, 2000, p. 169.

${ }^{13}$ STRECK, Lenio Luiz. Novo CPC terá mecanismos para combater decisionismos e arbitrariedades? Disponível em <http://www.conjur.com.br/2014-dez-18/senso-incomum-cpc-mecanismos-combaterdecisionismos-arbitrariedades>. Acesso em 10 jan 2015.
} 
Pode-se dizer sobre eles o que Canaris disse sobre os princípios ${ }^{14}$ : não possuem pretensão de exclusividade como fonte de deveres dos tribunais na formação dos precedentes judiciais. Muitos dos exemplos que serão apresentados são promíscuos, por não serem fiéis a apenas um dos deveres, ou, visto por outra ótica, são rebentos com duas mães.

No final das contas, o relevante será a soma dos deveres atribuídos ao tribunal a partir dos postulados da coerência e da integridade.

A essa soma, a esse amálgama pode-se dar o nome de consistência.

d) À quarta premissa. O dever de coerência e o dever de integridade servem ao atingimento de um fim: a jurisprudência há de ser consistente. É preciso extrair desse dispositivo do CPC o dever de o tribunal produzir uma jurisprudência consistente.

Uma jurisprudência pode ser coerente, mas inconsistente: o tribunal interpreta o Direito de modo coerente (do ponto de vista lógico), mas a argumentação que sustenta a ratio decidendi é frágil e lacunosa.

Uma jurisprudência pode ser íntegra, mas inconsistente: o tribunal decide com atenção à unidade do Direito, às peculiaridades de determinado microssistema ou às relações entre o processo e o Direito material, mas o faz a partir de distinções inconsistentes, teorias obsoletas ou sem o enfretamento de todos os argumentos suscitados em torno da controvérsia.

De fato, "consistência" parece ser um termo mais adequado para designar o conjunto formado por coerência e integridade; talvez a melhor opção fosse simplesmente dizer que os tribunais deverão zelar pela "consistência de sua jurisprudência". Qualificar uma jurisprudência como "consistente" é, claramente, considerá-la "íntegra e coerente".

A terminologia, aqui, também é um problema. As lições de Peczenik sobre "coerência", muitas vezes seguidas neste capítulo, servem, em alguns casos, para a compreensão do que aqui se denomina por "consistência"15 ou por "integridade".

\footnotetext{
${ }^{14}$ CANARIS, Claus-Wilhelm. Pensamento sistemático e conceito de sistema na ciência do direito. Introdução e Tradução por A. Menezes Cordeiro. $2^{\mathrm{a}}$ ed. Lisboa: Fundação Calouste Gulbenkian, 1996, p. 90.

${ }^{15} \mathrm{O}$ mesmo acontece com as lições de Aulis Aarnio. (AARNIO, Aulis. "The procedure of legal reasoning". Essays on the doctrinal Study of Law. Dordrecht: Springer, p. 145-146).
} 
MacCormick distingue "coerência" de "consistência", sendo que na tradução brasileira de seu livro, a palavra "consistency" foi traduzida como "coesão"16.

e) Quinta premissa: a condição mínima ${ }^{17}$ para que se possa considerar uma jurisprudência como íntegra e coerente é estar ela lastreada em precedentes bem fundamentados (art. 489, $\S 1^{\circ}$ e art. 927, §1 ${ }^{\circ}$, CPC).

A integridade e a coerência revelam-se no enfrentamento dos argumentos suscitados para a formação da tese jurídica do precedente. Tanto mais argumentos suportem a tese jurídica firmada, tanto mais consistente (íntegra e coerente) ela é ${ }^{18}$.

f) Sexta premissa: o art. 926 do CPC consagra dois exemplos de postulados hermenêuticos ${ }^{19}$, cuja utilização é necessária ao desenvolvimento judicial do Direito. Tanto na formação como na aplicação dos precedentes, os tribunais devem observar os postulados da coerência e da integridade.

g) Sétima premissa: a coerência e a integridade são pressupostos para que a jurisprudência possa ser universalizada, possa ser legitimamente aplicada a outros casos semelhantes. É da essência de um sistema de precedentes construídos de forma racional e não-autoritária que eles sejam universalizáveis. Não é legítimo universalizar o que não é íntegro ou coerente.

h) Finalmente, a oitava premissa: a verificação da integridade e da coerência da jurisprudência deve ser feita a partir da ponderação e do balanceamento de diversos critérios $^{20}$, que se relacionam entre si. Alguns desses critérios serão vistos a seguir. Na medida do possível, eles devem ser observados e não podem ser examinados isoladamente ${ }^{21}$

\subsection{Dever de coerência.}

\subsubsection{Generalidades.}

\footnotetext{
${ }^{16}$ MacCORMICK, Neil. Argumentação jurídica e teoria do direito. Waldéa Barcellos (trad.) São Paulo: Martins Fontes, 2009, p. 255.

${ }^{17}$ Falando apenas de "coerência", mas cuja lição se aplica perfeitamente ao quanto aqui se defende, PECZENIK, Alexsander. On law and reason, cit., p. 131.

${ }^{18}$ Adapta-se a lição de Peczenik, que se refere à coerência (PECZENIK, Alexsander. On law and reason, cit., p. 133).

${ }^{19}$ Sobre os postulados hermenêuticos de um modo geral e o postulado da coerência, de um modo especial, ÁVILA, Humberto. Teoria dos princípios. $12^{\mathrm{a}}$ ed. São Paulo: Malheiros Ed., 2011, p. 135144.

${ }^{20}$ PECZENIK, Alexsander. On law and reason, cit., p. 133.

${ }^{21}$ PECZENIK, Alexsander. On law and reason, cit., p. 144-145.
} 
A coerência entre duas normas pode ser visualizada em dimensão formal ou em dimensão substancial.

A coerência formal está ligada à ideia de não-contradição; a coerência substancial, à ideia de conexão positiva de sentido ${ }^{22}$. O dever de coerência deve ser concretizado em ambas as dimensões.

A exigência de coerência produz efeitos também em duas dimensões: interna e externa.

Do ponto de vista externo, os tribunais devem coerência às suas próprias decisões anteriores e à linha evolutiva do desenvolvimento da jurisprudência. A coerência é, nesse sentido, uma imposição do princípio da igualdade - casos iguais devem ser tratados igualmente, sobretudo quando o tribunal já tem um entendimento firmado. Não pode o tribunal contrariar o seu próprio entendimento, ressalvada, obviamente, a possibilidade de sua superação.

Julgar um caso é essencialmente distingui-lo de outro. É preciso, porém, que as distinções feitas pelos tribunais sejam coerentes.

Não há coerência, por exemplo, na distinção que o Supremo Tribunal Federal brasileiro fez entre inquérito penal e inquérito civil, para fins de aferição da competência legislativa respectiva - como será visto no item sobre integridade.

Também não há coerência na distinção que o Superior Tribunal de Justiça brasileiro fez, na vigência do CPC-1973, entre núcleos de prática jurídica de instituições federais de ensino e núcleos de prática jurídica de instituições particulares de ensino, reconhecendo apenas aos primeiros o benefício da dobra dos prazos processuais ${ }^{23}$.

Além disso, a dimensão externa do dever de coerência reforça o inafastável caráter histórico do desenvolvimento judicial do Direito: o direito dos precedentes forma-se paulatinamente, em uma cadeia histórica de decisões, que vão agregando sentido e dando densidade à norma jurídica geral construída a partir de um caso concreto.

A coerência impõe o dever de autorreferência, portanto: o dever de dialogar com os precedentes anteriores, até mesmo para superá-los e demonstrar o

\footnotetext{
22 ÁVILA, Humberto. Teoria dos princípios. 12a ed. São Paulo: Malheiros Ed., 2011, p. 140.

${ }^{23}$ Há precedente do STJ que não estende o benefício a núcleo de prática jurídica de entidade particular de ensino (STJ, $3^{\mathrm{a}} \mathrm{T}$., AgRg no AgRg no AgRg na MC 5.149/MG, rel. Min. Carlos Alberto Menezes Direito, j. 15.10.2002, publicado no DJ de 25.11.2002, p. 227). Há precedente do STJ que estende o benefício a núcleo de prática jurídica de entidade pública de ensino (STJ, 3a. T., REsp. n. 1.106.213/SP, rel. Mina. Nancy Andrighi, j. em 25.10.2011, publicado no DJe de 07.11.2011).
} 
distinguishing. O respeito aos precedentes envolve o ato de segui-los, distingui-los ou revogá-los, jamais ignorá-los ${ }^{24}$.

É bem conhecida a metáfora, elaborada por Dworkin, de que a construção judicial do Direito é um romance em cadeia: cada julgador escreve um capítulo, mas não pode deixar de dialogar com o capítulo anterior ${ }^{25}$, para que a história possa resultar em algo coerente. "A prática jurídica precisa se preocupar com o que foi feito anteriormente. (...) [a autorreferência] torna a prática mais comprometida com a coerência no discurso jurisdicional, por meio da criação de uma espécie de linha sequencial de decisões" ${ }^{26}$. Às vezes, nem mesmo o próprio julgador observa a sua própria cadeia decisória, submetido que está "às idiossincrasias decisórias de uma multiplicidade de assessores e analistas"27-28.

Muito a propósito, no particular, o enunciado n. 166 do Fórum Permanente de Processualistas Civis: "A aplicação dos enunciados das súmulas deve ser realizada a partir dos precedentes que os formaram e dos que os aplicaram posteriormente".

A coerência deve, ainda, ser observada no espaço e no tempo: "geograficamente, não se autorizando que a mesma situação jurídica seja tratada de forma injustificadamente diferente por órgãos de locais díspares; e historicamente, precisando respeitar sua atuação anterior ou justificar a modificação da posição que foi adotada com referência e cuidado com o passado e suas consequências"29.

\footnotetext{
${ }^{24}$ BARBOZA, Estefânia Maria de Queiroz. Precedentes judiciais e segurança jurídica - fundamentos e possibilidades para a jurisdição constitucional brasileira. São Paulo: Saraiva, 2014, p. 235.

${ }^{25}$ DWORKIN, Ronaldo. O Império do Direito. Jeferson Luiz Camargo (trad.). São Paulo: Martins Fontes, 2003, p. 275-277.

${ }^{26}$ MACÊDO, Lucas Buril de. Precedentes judiciais e o direito processual civil, cit., p. 271. O texto entre colchetes é nosso.

27 NEVES, Marcelo. "A 'desrazão' sem diálogo com a 'razão': teses provocatórias sobre o STF". Disponível em http://www.conjur.com.br/2014-out-18/desrazao-dialogo-razao-teses-provocatorias-stf, consultado em 17.02.2015.

${ }^{28}$ Embora se referindo ao dever de integridade, o que reforça a interseção que há entre ele e o dever de coerência, a lição de Dierle Nunes, Alexandre Bahia e Humberto Theodoro Jr. merece reprodução: "Em face da pressuposição brasileira de que os Ministros (e juízes) devem possuir liberdade decisória, cria-se um quadro de 'anarquia interpretativa' na qual nem mesmo se consegue respeitar a história institucional da solução de um caso dentro de um mesmo tribunal. Cada juiz e órgão do tribunal julgam a partir de um 'marco zero' interpretativo, sem respeito à integridade e ao passado de análise daquele caso; permitindo a geração de tantos entendimentos quantos sejam os juízes". (NUNES, Dierle; BAHIA, Alexandre; THEODORO Jr., Humberto. "Breves considerações da politização do judiciário e do panorama de aplicação no direito brasileiro: análise da convergência entre o civil law e o common law e dos problemas da padronização decisória". Revista de Processo. São Paulo: RT, 2010, n. 189, p. 43).

${ }^{29}$ MACÊDO, Lucas Buril. Precedentes Judiciais e o Direito Processual Civil. Salvador: Jus Podivm, 2014, p. 433.
} 
A dimensão interna do dever de coerência relaciona-se à construção do precedente e, por isso, ao dever de fundamentação. Coerência, nesse sentido, é uma dimensão da congruência que se exige de qualquer decisão judicial. Mas essa congruência não se limita ao aspecto lógico (dever de não produzir decisão contraditória) ${ }^{30}$; ela impõe outros atributos à decisão.

\subsubsection{Alguns critérios para aferição da coerência.}

Abaixo, alguns critérios de constatação da coerência do precedente judicial e, por tabela, da jurisprudência.

\subsubsection{Conformidade com o repertório conceitual da Teoria Geral do Direito e da Dogmática Jurídica.}

A decisão deve estar de acordo com o repertório conceitual da Teoria Geral do Direito e da Ciência Dogmática do Direito.

Porque estabelece o compêndio dos conceitos jurídicos fundamentais (prova, capacidade, cognição, ato processual etc.), a Teoria Geral do Direito tem uma função bloqueadora: a solução jurídica que se der a um problema jurídico somente será aceitável se estiver em conformidade com a pauta conceitual por ela fornecida ${ }^{31}$. Uma das funções do saber dogmático (o conhecimento indispensável à solução dos problemas jurídicos) é, exatamente, institucionalizar a tradição jurídica, "gerando segurança e uma base comum para os técnicos do direito" ${ }^{2}$. Porque estabelece o compêndio dos conceitos jurídico-positivos (apelação, inspeção judicial, reconvenção etc.), a Ciência Dogmática do Direito também exerce essa mesma função bloqueadora.

À doutrina cabe a função de apontar "critérios precisos, que permitam processos discursivos transparentes e controles intersubjetivos" ${ }^{\prime 3}$ das decisões. Em

\footnotetext{
${ }^{30}$ PECZENIK, Alexsander. On law and reason, cit., p. 131. A teoria sobre coerência desenvolvida por Alexsander Peczenik serve para a compreensão do sistema jurídico, da dogmática jurídica e da decisão judicial (PECZENIK, Alexsander. "Certainty or coherence", cit., p. 169).

31 FERRAZ Jr., Tércio Sampaio. A ciência do direito. $2^{\mathrm{a}}$ ed. São Paulo: Atlas, 1980, p. 62. Especificamente sobre a função bloqueadora da Teoria Geral do Processo, DIDIER Jr., Fredie. Sobre a Teoria Geral do Processo. $2^{\mathrm{a}}$ ed. Salvador: Editora Jus Podivm, 2013, p. 98-100.

${ }^{32}$ FERRAZ JR., Tércio Sampaio. Introdução ao estudo do direito - Técnica, decisão e dominação. São Paulo: Atlas, 1994, p. 88.

${ }_{33}$ ÁVILA, Humberto. "A doutrina e o Direito Tributário". Fundamentos do Direito Tributário. Humberto
} 
suma: "não é qualquer interpretação que vale, mas apenas aquelas que resultam de uma argumentação conforme os padrões dogmáticos"34.

A força persuasiva da doutrina no exercício da função jurisdicional será maior ou menor conforme a tradição jurídica de cada país; mas não é razoável supor que o órgão julgador simplesmente ignore a produção da ciência jurídica ${ }^{35}$.

Sem o manancial teórico fornecido pela ciência jurídica, a interpretação justa do Direito torna-se, rigorosamente, impossível ${ }^{36}$. A principal utilidade da ciência jurídica é exatamente possibilitar o uso coerente $^{37}$ dos inúmeros conceitos jurídicos ${ }^{38}$.

\subsubsection{Recondução a uma mesma norma superior.}

A coerência entre duas normas (entre duas normas-precedente, por exemplo) revela-se, também, quando ambas podem ser justificadas com base em um mesmo princípio ou em um mesmo conjunto de princípios que estejam hierarquicamente em nível superior. Ou seja: é preciso que essas duas normas "façam sentido", "em virtude de serem racionalmente relacionadas como um conjunto instrumental ou intrinsecamente voltado para a realização de alguns valores comuns"39.

\footnotetext{
Ávila (org.). São Paulo: Marcial Pons, 2012, p. 230.

${ }^{34}$ FERRAZ JR., Tércio Sampaio. Introdução ao estudo do direito - Técnica, decisão e dominação, $2^{\mathrm{a}}$ ed., cit., p. 51

${ }^{35}$ PECZENIK, Aleksander. Scientia juris - legal doctrine as knowledge of law and as a source of law. Dordrecht: Springer, 2005, p. 7.

36 "Nenhuma tentativa séria de elucidar a natureza do direito ou das leis, ou de uma parte ou ramo de estudo jurídico, poderá deixar de incluir alguma análise de termos ou de conceitos". (MacCORMICK, Neil. "Analítica (abordagem do direito)" Dicionário Enciclopédico de Teoria e Sociologia do Direito. André-Jean Arnaud (org.). Tradução para a língua portuguesa sob a direção de Vicente de Paulo Barreto. Rio de Janeiro: Renovar, 1999. p. 25.)

37 "The doctrine plays an important role because it aims at rationality". "A teoria exerce um importante papel porque visa à racionalidade", em tradução livre. (PECZENIK, Alexsander. On law and reason, cit., p. 295.)

${ }^{38}$ DIMOULIS, Dimitri. O positivismo jurídico. São Paulo: Método, 2006, p. 42.

39 MacCORMICK, Neil. Retórica e o Estado de Direito. Conrado Hübner Mendes e Marcos Paulo Veríssimo (trad.) Rio de Janeiro: Elsevier, 2008, p. 252. Nesse sentido, MICHELON, Claudio. "Princípios e coerência na argumentação jurídica". Direito e interpretação - racionalidades e instituições. Ronaldo Porto Macedo Jr. e Catarina Helena Cortada Barbieri (org.). São Paulo: Saraiva, 2011, p. 267; ÁVILA, Humberto. Teoria dos princípios. 12a ed. São Paulo: Malheiros Ed., 2011, p. 136; MITIDIERO, Daniel. Cortes superiores e cortes supremas - do controle à interpretação, da jurisprudência ao precedente. São Paulo: RT, 2013, p. 86.
} 
Define-se a coerência, aqui, como uma relação de justificação (de argumentação) entre duas normas ${ }^{40}$.

Um exemplo. As regras extraídas dos arts. 139, IX, 282, §2 , 317, 321, 485, $\S 7^{\circ}, 487,932$, p. único e 1029, $\S 3^{\circ}$, do CPC, formam um conjunto coerente de normas que se justificam em um mesmo princípio: o princípio da primazia da decisão de mérito (art. $4^{\circ}, \mathrm{CPC}$ ). Se o tribunal ora segue essa linha no exame das questões de admissibilidade da petição inicial, ora segue linha oposta no exame da admissibilidade de incidentes processuais, produz uma jurisprudência incoerente.

Outro exemplo. Um tribunal que decida, em um caso, que a união homoafetiva é família, para fim sucessório, e, em outro, que não é família, para fim previdenciário, produz decisões incoerentes, pois não é possível reconduzi-las a uma norma superior comum.

Mais um exemplo. Há diversas normas que remetem ao princípio do respeito ao autorregramento da vontade no processo civil brasileiro. Elas, portanto, demonstram a coerência do sistema jurídico, no particular: a) amplo regramento da mediação ou conciliação (arts. 165 a 175, CPC); b) estruturação do procedimento de modo a pôr a tentativa de autocomposição como ato anterior ao oferecimento da defesa pelo réu (arts. 334 e 695, CPC); c) permissão de homologação judicial de acordo extrajudicial de qualquer natureza (art. 515, III; art. 725, VIII, CPC); d) permissão que, no acordo judicial, seja incluída matéria estranha ao objeto litigioso do processo (art. 515, §2, CPC); e) permissão de acordos processuais (sobre o processo, não sobre o objeto do litígio) atípicos (art. 190, CPC); f) incentivo à arbitragem (Lei n. 9.307/1996); g) existência de vários negócios jurídicos processuais típicos (art. 63; art. 65; art. 168; art. 225; art. 311, II; art. 337, §6; art.

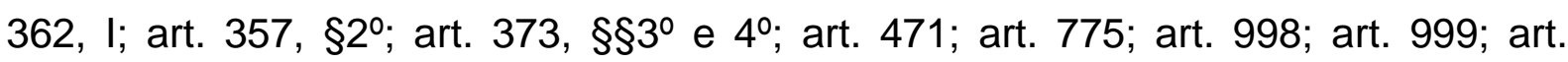
$1.000, \mathrm{CPC})$.

\subsubsection{Conformidade com a regra que impõe requisitos para a congruência interna da decisão.}

40 MICHELON, Claudio. "Princípios e coerência na argumentação jurídica". Direito e interpretação racionalidades e instituições. Ronaldo Porto Macedo Jr. e Catarina Helena Cortada Barbieri (org.). São Paulo: Saraiva, 2011, p. 267. 
O dever de coerência impõe que o precedente observe, obviamente, a regra de congruência interna das decisões judiciais.

O precedente precisa ser certo, claro e coerente. Se um tribunal disser, por exemplo, que uma decisão é inexistente, mas, ao mesmo tempo, reputá-la rescindível, estará violando claramente o dever de coerência, pois algo não pode ser simultaneamente inexistente e rescindível.

\subsubsection{Dever de integridade.}

O dever de integridade relaciona-se com a ideia de unidade do Direito.

Embora o termo "integridade" esteja muito relacionado a Ronald Dworkin, este ensaio não interpretará o enunciado normativo do art. 926 do CPC brasileiro exclusivamente com base no seu pensamento. As ideias de Dworkin são importantíssimas para a compreensão do assunto, mas não são a única fonte para a concretização do dever de integridade no Direito brasileiro. Essa opção decorre da premissa teórica do professor estadunidense, segundo a qual somente há uma resposta correta para um problema jurídico. Neste ponto, essa prestigiada teoria da interpretação do Direito não é a seguida neste ensaio. A interpretação é, essencialmente, uma atividade de recriação e, também, de escolha de significado, "ainda que lógica e argumentativamente guiada"41. A teoria da "única resposta certa" não resolve, por exemplo, o problema da interpretação das cláusulas gerais e dos conceitos jurídicos indeterminados, textos normativos genuinamente ambíguos ${ }^{42}$.

A observância do dever de integridade supõe que o tribunal adote certas posturas ao decidir. Eis algumas delas.

a) Decidir em conformidade com o Direito, observada toda a sua complexidade (normas constitucionais, legais, administrativas, negociais, precedentes etc.); não se admite, por exemplo, decisão com base em "Direito alternativo".

${ }^{41}$ MITIDIERO, Daniel. Cortes superiores e cortes supremas - do controle à interpretação, da jurisprudência ao precedente. São Paulo: RT, 2013, p. 58.

${ }^{42}$ AARNIO, Aulis. The rational as reasonable - a treatise on legal justification. Dordrecht: D. Reidel, 1987, p. 165. 
Nesse aspecto, o dever de integridade impede o voluntarismo judicial e argumentações arbitrárias ${ }^{43}$. “Um caso judicial só se pode resolver pela totalidade do ordenamento jurídico, e não por uma só se duas partes, tal como o peso todo de uma esfera gravita sobre a superfície em que jaz, embora seja só um o ponto em que toma contacto." 44

b) Decidir em respeito à Constituição Federal, como fundamento normativo de todas as demais normas jurídicas. O dever de integridade é, nesse sentido, uma concretização do postulado da hierarquia, "do qual resultam alguns critérios importantes para a interpretação das normas, tais como o da interpretação conforme a Constituição"45.

c) Compreender o Direito como um sistema de normas, e não um amontoado de normas. O dever de integridade é, nesse sentido, uma concretização do postulado da unidade do ordenamento jurídico, "a exigir do intérprete o relacionamento entre a parte e o todo mediante o emprego das categorias de ordem e de unidade" 46 .

$E$, consequentemente, reconhecer a existência de microssistemas normativos para, quando for o caso, decidir conforme as regras desse mesmo microssistema.

d) Observar as relações íntimas e necessárias entre o Direito processual e o Direito material.

Um exemplo. O tribunal, ao interpretar uma norma processual, demonstra as relações que ela mantém com uma determinada norma material - como no caso de interpretação das normas relativas à denunciação da lide, por exemplo. Ao fazer isso, o tribunal robustece a sua fundamentação, por estabelecer as conexões normativas entre os diversos ramos do Direito. Com essas conexões normativas, o tribunal, por observar o dever de integridade, torna a sua decisão ainda mais consistente 47 .

e) Enfrentar, na formação do precedente, todos os argumentos favoráveis e contrários ao acolhimento da tese jurídica discutida. Esse desdobramento do dever de integridade está expressamente consagrado no $\$ 2^{\circ}$ do

\footnotetext{
43 AARNIO, Aulis. "The procedure of legal reasoning". Essays on the doctrinal Study of Law. Dordrecht: Springer, p. 145.

${ }^{44}$ Lição de Carlos Cossio, extraída de BORGES, José Souto Maior. O contraditório no processo judicial (uma visão dialética). São Paulo: Malheiros Ed., 1996, p. 91.

${ }_{45}$ ÁVILA, Humberto. Teoria dos princípios. 12a ed. São Paulo: Malheiros Ed., 2011, p. 136.

${ }^{46}$ ÁVILA, Humberto. Teoria dos princípios. 12a ed. São Paulo: Malheiros Ed., 2011, p. 136.

${ }^{47} \mathrm{Na}$ linha do que defende Peczenik, que, não obstante, usa o termo "coerência", em vez de "consistência" (PECZENIK, Alexsander. On law and reason, cit., p. 138).
} 
art. 984 e no $\S 3^{\circ}$ do art. 1.038 do CPC - também nesse sentido o enunciado 305 do Fórum Permanente de Processualistas Civis: "No julgamento de casos repetitivos, o tribunal deverá enfrentar todos os argumentos contrários e favoráveis à tese jurídica discutida". 48

Alguns exemplos de entendimentos que não observam o dever de integridade:

i) decisão que não reconheça capacidade processual do Ministério Público para propor mandado de segurança coletivo, por não encontrar referência a ele no art. 21 da Lei 12.016/2009, ignora a existência do microssistema de tutela coletiva de direitos $^{49}$;

ii) o acórdão do STF que considera que o inquérito penal tem natureza processual e é, por isso, tema de competência legislativa privativa da União (art. 22, I, CF) ${ }^{50}$ fere a integridade (e também a coerência) quando há precedente dessa mesma Corte no sentido de que o inquérito civil é procedimento administrativo, para fins de reconhecer a competência dos Estados para legislar supletiva ou suplementarmente sobre essa matéria (art. 24, XI, CF) ${ }^{51}$;

iii) decisão que não considerasse como obrigatória a intimação das fazendas públicas na ação de usucapião imobiliária de procedimento comum, porque silencia o CPC a respeito do assunto, violaria o dever de integridade. Se essa intimação é exigida no procedimento administrativo de reconhecimento da usucapião imobiliária (art. 1.071, CPC), tanto mais ela se justifica no procedimento judicial, que tem aptidão para a coisa julgada (nesse sentido, enunciado n. 25 do Fórum Permanente de Processualistas Civis);

iv) decisão que considera proibido o oferecimento à penhora, pelo executado, de bem de família disponível, viola o dever de integridade, pois incompatível com o sistema do Direito privado que permite que esse mesmo bem

\footnotetext{
48 Para Ávila, a "completude" (conjunto de proposições contém todos os elementos e suas negações) é um atributo da coerência e está relacionada à ideia de integridade (ÁVILA, Humberto. Teoria dos princípios. $12^{\mathrm{a}}$ ed. São Paulo: Malheiros Ed., 2011, p. 140).

49 DIDIER Jr., Fredie; ZANETI Jr., Hermes. "O mandado de segurança coletivo e a Lei n. 12.016/2009". In: Eduardo Arruda Alvim; Glauco Gumerato Ramos; Gustavo de Medeiros Melo; José Henrique Mouta Araújo (Org.). O Novo Mandado de Segurança. Belo Horizonte: Fórum, 2010, p. 227-238.

${ }^{50}$ Cf. STF, Pleno, ADI n. 1615-6 MC/DF, rel. Min. Néri da Silveira, j. em 12.6.1997, publicada no DPJ de 5.11.1997; STF, Pleno, ADI n. 3.896, rel. Min. Carmen Lúcia, j. em 04.06.2008 e publicada no DJe de 08.08.2008.

${ }^{51}$ STF, Pleno, MC na ADI n. 1.285, rel. Min. Moreira Alves, j. em 24.10.1995, publicada no DPJ de 23.03.2001.
} 
seja alienado, onerosamente (vendido ou hipotecado, por exemplo) ou gratuitamente (doado); se o bem pode ser alienado pelo seu proprietário, pode ser oferecido por ele à penhora, primeira etapa do procedimento de alienação judicial do bem.

\section{REFERÊNCIAS}

AARNIO, Aulis. The procedure of legal reasoning. Essays on the doctrinal Study of Law. Dordrecht: Springer, 2010.

AARNIO, Aulis. The rational as reasonable - a treatise on legal justification. Dordrecht: D. Reidel, 1987.

ATAÍDE JUNIOR, Jaldemiro. O princípio da inércia argumentativa diante de um sistema de precedentes em formação no Direito brasileiro. Revista de Processo. São Paulo: RT, 2014.

ATAIIDE JUNIOR, Jaldemiro. O princípio da inércia argumentativa diante de um sistema de precedentes em formação no Direito brasileiro. Revista de Processo. São Paulo: RT, 2014.

ÁVILA, Humberto. "A doutrina e o Direito Tributário". Fundamentos do Direito Tributário. Humberto Ávila (org.). São Paulo: Marcial Pons, 2012.

ÁVILA, Humberto. Teoria dos princípios. 12ª ed. São Paulo: Malheiros Ed., 2011.

BARBOZA, Estefânia Maria de Queiroz. Precedentes judiciais e segurança jurídica - fundamentos e possibilidades para a jurisdição constitucional brasileira. São Paulo: Saraiva, 2014.

BORGES, José Souto Maior. O contraditório no processo judicial (uma visão dialética). São Paulo: Malheiros Ed., 1996.

BRASIL. Lei 13.115/2015 - Código de Processo Civil. 16 de março de 2015.

CANARIS, Claus-Wilhelm. Pensamento sistemático e conceito de sistema na ciência do direito. Introdução e Tradução por A. Menezes Cordeiro. $2^{\mathrm{a}}$ ed. Lisboa: Fundação Calouste Gulbenkian, 1996.

DIDIER Jr., Fredie. Sobre a Teoria Geral do Processo. $2^{\mathrm{a}}$ ed. Salvador: Editora Jus Podivm, 2013 
DIDIER Jr., Fredie; CUNHA, Leonardo Carneiro da. Curso de Direito Processual Civil. 12a ed. Salvador: Editora Jus Podivm, 2014.

DIDIER Jr., Fredie; ZANETI Jr., Hermes. O mandado de segurança coletivo e a Lei n. 12.016/2009. In: Eduardo Arruda Alvim; Glauco Gumerato Ramos; Gustavo de Medeiros Melo; José Henrique Mouta Araújo (Org.). O Novo Mandado de Segurança. Belo Horizonte: Fórum, 2010.

DIMOULIS, Dimitri. O positivismo jurídico. São Paulo: Método, 2006.

DWORKIN, Ronaldo. O Império do Direito. Jeferson Luiz Camargo (trad.). São Paulo: Martins Fontes, 2003.

FERRAZ Jr., Tércio Sampaio. A ciência do direito. 2a ed. São Paulo: Atlas, 1980. Introdução ao estudo do direito - Técnica, decisão e dominação. São Paulo: Atlas, 1994.

MacCORMICK, Neil. "Analítica (abordagem do direito)" Dicionário Enciclopédico de Teoria e Sociologia do Direito. André-Jean Arnaud (org.). Tradução para a língua portuguesa sob a direção de Vicente de Paulo Barreto. Rio de Janeiro: Renovar, 1999.

Argumentação jurídica e teoria do direito. Waldéa Barcellos (trad.) São Paulo: Martins Fontes, 2009.

Retórica e o Estado de Direito. Conrado Hübner Mendes e Marcos Paulo Veríssimo (trad.) Rio de Janeiro: Elsevier, 2008.

MACÊDO, Lucas Buril. Precedentes Judiciais e o Direito Processual Civil. Salvador: Jus Podivm, 2014.

MICHELON, Claudio. "Princípios e coerência na argumentação jurídica". Direito e interpretação - racionalidades e instituições. Ronaldo Porto Macedo Jr. e Catarina Helena Cortada Barbieri (org.). São Paulo: Saraiva, 2011.

MITIDIERO, Daniel. Cortes superiores e cortes supremas - do controle à interpretação, da jurisprudência ao precedente. São Paulo: RT, 2013.

NEVES, Marcelo. A 'desrazão' sem diálogo com a 'razão': teses provocatórias sobre o STF". Disponível em http://www.conjur.com.br/2014-out-18/desrazaodialogo-razao-teses-provocatorias-stf, consultado em 17.02.2015. 
NUNES, Dierle; BAHIA, Alexandre; THEODORO Jr., Humberto. Breves considerações da politização do judiciário e do panorama de aplicação no direito brasileiro: análise da convergência entre o civil law e o common law e dos problemas da padronização decisória. Revista de Processo. São Paulo: RT, No 189, 2010.

PECZENIK, Aleksander. Scientia juris - legal doctrine as knowledge of law and as a source of law. Dordrecht: Springer, 2005.

Certainty or coherence. The reasonable as rational? On legal argumentation and justification. Festschrift for Aulis Aarnio. Berlin: Duncker \& Humblot, 2000.

. On law and reason. Lexington: Springer, 2009.

PICARDI, Nicola. La vocazione del nostro tempo per la giurisdizione. Rivista Trimestrale di Diritto e Procedura Civile. Milano: Giuffrè, 2004.

SANTOS, Ernane Fidélis. Manual de Direito Processual Civil. 6ª ed. São Paulo: Saraiva, 1998.

STRECK, Lenio Luiz. Novo CPC terá mecanismos para combater decisionismos e arbitrariedades? Disponível em <http://www.conjur.com.br/2014-dez-18/sensoincomum-cpc-mecanismos-combater-decisionismos-arbitrariedades>. Acesso em 10 jan 2015.

SUPREMO TRIBUNAL FEDERAL. Pleno, ADI n. 1615-6 MC/DF, rel. Min. Néri da Silveira, j. em 12.6.1997, publicada no DPJ de 5.11.1997.

SUPREMO TRIBUNAL FEDERAL. Pleno, ADI n. 3.896, rel. Min. Carmen Lúcia, j. em 04.06.2008 e publicada no DJe de 08.08.2008.

SUPREMO TRIBUNAL FEDERAL. Pleno, MC na ADI n. 1.285, rel. Min. Moreira Alves, j. em 24.10.1995, publicada no DPJ de 23.03.2001.

VIGLIAR, José Marcelo Menezes. Uniformização de jurisprudência - segurança jurídica e dever de uniformizar. São Paulo: Atlas, 2003.

ZANETI JR., Hermes. O Valor Vinculante dos Precedentes. Salvador: JusPodivm, 2014. 